\title{
Numerical Modelling and Simulation of the Aluminothermic Welding of Rails: Heat Transfer and Solid-Liquid Phase Change
}

\author{
Ravi Govindram Kewalramani ${ }^{1}$, Ingo Riehl' ${ }^{1}$ Jan Hantusch², Joerg Keichel ${ }^{3}$, Martin Niederkrueger ${ }^{4}$, \\ Tobias Fieback ${ }^{1}$ \\ ${ }^{1}$ Chair of Technical Thermodynamics, TU Bergakademie Freiberg \\ Gustav-Zeuner-Str. 7, 09599 Freiberg/Saxony, Germany \\ Ravi.Kewalramani@ttd.tu-freiberg.de; Ingo.Riehl@ttd.tu-freiberg.de; Tobias.Fieback@ttd.tu-freiberg.de \\ ${ }^{2}$ Technology Innovation Center, Goldschmidt Holding GmbH, \\ Am Schenkberg 20, 04349 Leipzig, Germany \\ Jan.Hantusch@goldschmidt.com \\ ${ }^{3}$ Elektro-Thermit GmbH \& Co. KG. \\ Chemiestr. 24, 06132 Halle (Saale), Germany \\ Joerg.Keichel@goldschmidt.com \\ ${ }^{4}$ Goldschmidt Holding GmbH \\ Hugo-Licht-Str. 3, 04109 Leipzig, Germany \\ Martin.Niederkrueger@goldschmidt.com
}

\section{Extended Abstract}

The aluminothermic (AT) welding, a.k.a. THERMIT ${ }^{\circledR}$ welding or thermite welding (TW), is well known for its simplicity, robustness, portability and economic usage for joining and repairing of rails. It has been successfully used all around the world for over a century. It is, in principle, a casting process in which the molten metal from the crucible is settled in a preheated mould and then allowed to solidify. For an efficient and high-quality weld, the knowledge of each stage involved during welding, such as preheating, thermite reaction, mould filling (pouring), cooling (solidification) process, is significant.

The present work numerically investigates the thermal conditions involved during the preheating and cooling stages of the AT welding process along with solid-liquid phase change. The steel-slag system is considered as two immiscible fluids and has been modelled using the Volume of Fluid (VOF) method [1, 2]. The enthalpy-porosity technique [3] has been employed to predict the temporal and spatial evolution of the solid-liquid phase front and to enforce the velocity field in the solid region to zero. The complete multi-physics model is developed and implemented in the open-source Finite Volume Method (FVM) based Computational Fluid Dynamics (CFD) software, OpenFOAM ${ }^{\circledR}$, and has been rigorously validated in our previous work [4].

A typical THERMIT ${ }^{\circledR}$ SkV-ELITE L25 mould assembly for a 60E1 rail profile has been investigated, here SkV (German: Schnellschweißverfahren mit kurzer Vorwärmung) means rapid welding process with short preheating and ELITE is a type of mould used for the AT welding of rails. Taking advantage of two symmetry planes, only one-fourth of the computational domain is considered for the simulation. To predict the temperature distribution in the rail at the end of the preheating stage, simulations are carried out by prescribing a predefined heat flux profile on the rail end inside the mould. The heat flux profile is calculated using the temperature measurements in the rail obtained from experiments as discussed by Chen et al. [5]. For simplicity, the mould filling simulation is not performed. Instead, it is assumed that the mould is already filled with a constant molten metal temperature of $2473 \mathrm{~K}$. Furthermore, the heat transfer between the mould and the molten metal is neglected (i.e., the insulated boundary condition is imposed on the mould walls).

At the beginning of the cooling stage, as the hot molten metal is in direct contact with the rail surface inside the mould, the primary heat flux inside the mould goes through the relatively cold rail. The density of the molten metal close to the rail surface increases and results in buoyancy-driven thermal convection. As time progresses, the temperature gradients in the molten metal decrease due to the heat loss through the rail, thereby weakening the velocity field in the molten metal. 
The solid-liquid phase front inside the mould progresses from the rail end towards the weld centre and from rail base to rail head, such that the temporal and spatial evolution of the solid-liquid phase front results in a V-shaped solidification.

Finally, the simulation results are qualitatively compared with experiments conducted at Goldschmidt Holding GmbH. The predicted temperature profiles in the rail during preheating and cooling stage, fusion zone (FZ) and heat-affected zone (HAZ) have shown a good agreement with experiments.

Keywords: Aluminothermic welding, Buoyancy-driven flow, CFD, Multiphase, OpenFOAM ${ }^{\circledR}$, Rail joining, Solid-liquid phase change, Thermal convection.

\section{References}

[1] C. W. Hirt and B. D. Nichols, "Volume of Fluid (VOF) Method for the Dynamics of Free Boundaries," Journal of Computational Physics, vol. 39, pp. 201-225, 1981.

[2] H. Rusche, "Computational fluid dynamics of dispersed two-phase flows at high phase fractions," Ph.D. dissertation, University of London, 2002.

[3] V. R. Voller and C. Prakash, "A fixed grid numerical modelling methodology for convection-diffusion mushy region phase change problems," International Journal of Heat and Mass Transfer, vol. 30(8), pp. 1709-1719, 1987.

[4] R. G. Kewalramani, S. Pose, I. Riehl and T. Fieback, "Solid-Liquid Phase Change in the Presence of Gas Phase: Numerical Modeling and Validation," Journal of Fluid Flow, Heat and Mass Transfer, vol. 7, pp. 1-11, 2020.

[5] Y. Chen, F. V. Lawrence, C. P. L. Barkan, and J. A. Dantzig, "Heat transfer modelling of rail thermite welding," Proceedings of the Institution of Mechanical Engineers, Part F: Journal of Rail and Rapid Transit, vol. 220, pp. 207217, 2006. 